\title{
ДИНАМИЧЕСКИЕ ПОКАЗАТЕЛИ ОРГАНИЗАЦИИ В УПРАВЛЕНИИ РИСКАМИ ИННОВАЦИОННОЙ ДЕЯТЕЛЬНОСТИ НА РАЗНЫХ СТАДИЯХ ЖИЗНЕННОГО ЦИКЛА ИННОВАЦИЙ
}

\author{
(c) 2021 Сырова Татьяна Николаевна \\ преподаватель кафедры менеджмента \\ Самарский государственный экономический университет, Россия, Самара \\ E-mail:Ts260679@yandex.ru
}

В статье проанализированы основные подходы к определению жизненного цикла инноваций, рассмотрены характеристики каждой стадии жизненного цикла и определена степень значимости рисков инновационной деятельности, как в принятии решений по разработке инноваций, так и в достижении поставленных целей инновационной деятельности. Для обеспечения стабильности результата инноваций предложены к рассмотрению основные динамические показатели деятельности инновационной организации и методы по их управлению и взаимодействию, поставлен вопрос о стратегическом характере организации процесса инновационной деятельности.

Ключевые слова: инновация, инновационная деятельность, жизненный цикл инноваций, управление инновациями, риск инновационной деятельности, управление рисками инновационной деятельности, динамические показатели инновационной деятельности

Инновационная деятельность определена как основная стратегическая цель экономики РФ и является основным вектором ее развития. Это определяется расширенным спектром возможностей по обеспечению благосостояния граждан и государства в целом, за счет повышения конкурентоспособности и рентабельности бизнеса посредством внедрения инноваций.

Значимость инновационной деятельности сложно переоценить как в рамках отдельно взятых компаний, так и для экономики государства в целом. Инновации на сегодняшний день являются основой жизнеобеспечения и развития в любой сфере.

Но при этом, широкое распространение инноваций крайне затруднено в виду высокого уровня рисков. Риски инновационной деятельности возможны на любом этапе жизненного цикла инноваций. Более того, в зависимости от этапа у них существуют свои характерные особенности.

В связи с чем, отечественные и мировые ученые работают над решением проблемы по идентификации, учету и разработки программ по управлению рисками с целью минимизировать возможность их возникновения или уменьшить последствия возникших рисков в ходе инновационной деятельности.

Сложности систематизации данных и разработки унифицированных программ заключа- ются в основных характеристиках инноваций - уникальности и мультикритериальности не только видов инновационной деятельности, но и каждого отдельного проекта.

В связи с чем, для разработки эффективных программ по управлению рисками инновационной деятельности необходимо учитывать все характеристики инновационного проекта и на каждом этапе их жизненного цикла.

Жизненный цикл инноваций по своим характеристикам совпадает с циклом любого экономического процесса и напрямую связан с эффективностью и результативностью инноваций, которая заключается в фактической коммерческой или иной выгоде для производителя/ разработчика/инвестора.

Жизненные циклы инноваций различаются как по видам инноваций, так и по сферам деятельности разработок. Отличия в основном касаются продолжительности цикла или определенных стадий деятельности внутри цикла, а также особенностей развития самих стадий.

Но, несмотря на это ученые выделяют единую структуру жизненного цикла инноваций, с условием их разделения на жизненный цикл продукта и жизненный цикл операции.

Выделяют 7 основных стадий жизненного цикла нового продукта:

1. Разработка нового продукта. На этой стадии компания-новатор непосредственно ор- 
ганизует инновационный процесс и здесь же происходят основные финансовые инвестиции в проект.

2. Выход на рынок нового продукта. Здесь начинается возврат инвестиций. Длительность этой стадии зависит от эффективности рекламы, слаженности работы отдела продаж, уровня инфляции.

3. Развитие рынка. На этой стадии происходит рост объема продаж нового продукта на рынке.

4. Стабилизация рынка. Стабилизация показывает уровень насыщения рынка новым продуктом и остановку роста объема продаж.

5. Уменьшение рынка. Характеризуется спадом продаж.

При диверсификации рынка и активной маркетинговой политике компании по восстановлению нового продукта на рынке возможны еще 2 стадии жизненного цикла: стадия подъема рынка и стадия падения $[1,5]$.

Что касается жизненного цикла новой операции, то здесь выделяют 4 стадии:

1. Разработка новой операции и ее оформление в виде документа. На данной стадии происходит определение необходимости разработки инновации, поиск идеи, разработка алгоритмов и пр. Как и в первой стадии при разработке нового продукта, для этой стадии характерны максимальные финансовые вложения.

2. Реализация операции связана либо с ее внедрением внутри самой компании-новатора, либо с ее реализацией на рынке (в зависимости от цели создания операции);

3. Стабилизация рынка характеризуется насыщением рынка.

4. Падение рынка - снижение актуальности операции внутри компании или падение продаж на рынке. [1]

Кроме того, ряд ученых, рассматривают как временные этапы жизненного цикла нововведения непосредственно инновационных процесс.

И.Т.Балабанов в своих работах рассматривает инновационный процесс как структуру последовательных взаимосвязанных элементов. К ним он относит:

1. Инициация - это комплекс мероприятий по материализации идеи инновации (от выбора цели инновации, постановки задачи для инновации, поиске идеи, ее техническом, экономическом обосновании и непосредственной выражении в виде описания продукта).
2. Маркетинг инновации - маркетинговые исследования инновации, в ходе которых изучается спрос, производится расчет объемов, оцениваются потребительские ожидания относительно продукта и на основании них определяются потребительские свойства и характеристики инновационного продукта.

3. Выпуск (производство) инновации - непосредственно изготовление инновационного продукта и его апробация;

4. Реализация инновации - выпуск на рынок первой (ограниченной) партии продукта с целью анализа спроса и оценки емкости рынка;

5. Продвижение инновации - комплекс мероприятий, направленный на реализацию и внедрения инноваций на рынке (информирование, реклама, организация процесса торговли и пр.);

6. Оценка экономической эффективности инновации - анализ результатов 4 и 5 стадии и расчет показателей экономической эффективности, принятие решения о масштабировании проекта;

7. Диффузия инновации - распространение инновации на новых рынках. [2, 11]

Как мы уже отмечали ранее, на каждом из этапов жизненного цикла инноваций существует возможность возникновения рисковых ситуаций. Более того, для инновационной деятельности часто характерны и непрогнозируемые риски, которые было невозможно предположить при изначальной разработке и оценке рисков. К данным рискам можно отнести любую ситуацию форс-мажора, их сложно идентифицировать и предугадать. Кроме того, если посмотреть на любой прогнозируемый риск со стороны, к примеру, невозможности реализации разработанной программы управления риском, он тоже будет являться непрогнозируемым.

Собственно, именно непрогнозируемые риски и являются одной из значимых проблем, тормозящих развитие и широкое распространение инновационной деятельности $[3,6,10]$.

В связи с чем, ученые активно занимаются разработками в этой области. В том числе и автор, в своих научных исследованиях проводит анализ взаимосвязанных систем, которые помогают компаниям минимизировать возможность наступления рисковых ситуаций, либо последствия для организаций при их возникновении, в том числе и при возникновении форс-мажор- 
ных ситуаций.

На основании результатов проведенных научных исследования были выявлены основные динамические показатели компаний, которые влияют на эффективность и стабильность инновационной деятельности организации, а также повышают (в ряде случаев - обеспечивают) толерантность компаний к воздействиям рисковых ситуаций.

Слаженная работа и регулярный анализ состояния этих показателей, фактически поможет обеспечить планируемый эффект от инновационной деятельности.

Динамические показатели деятельности инновационной организации:

1) Менеджмент инноваций - управление инновациями.

На самом начальном этапе инновационной деятельности - идеи о формировании инновационного портфеля - необходимо рассмотреть основополагающий вопрос: инновационный потенциал компании и мотивация инновационной деятельности.

Следует отметить, что часто решения об инновациях принимаются не в рамках стратегического развития компании, а под воздействием внешних факторов, модных тенденций, инновационного развития конкурентов, рекомендаций сотрудников или в качестве антикризисной меры компании.

При этом, основная цель - быстрое решение возникших в данный момент, проблем организации и полная неготовность к возникновению незапланированных ситуаций.

Данный подход в существенном количестве случаев приводит к замораживанию или отказу от инновационной деятельности в случае наступления рисковых ситуаций. Более того, этот подход сам по себе инициирует формирование многочисленного количества рисков инновационной деятельности.

Во избежание подобного рода последствий, крайне важно иметь стратегическую направленность организации на инновационное развитие, которая в себя включает оценку всех возможностей и ресурсов компании к развитию инноваций, мобильность организационной структуры компании для организации инновационного процесса, готовность и лояльность персонала к инновационной деятельности, компетентность специалистов-новаторов и пр.

Чем более детально будет проработан про- цесс организации инновационной деятельности, тем качественнее будет результат от самих инноваций $[7,9]$.

2) Информационная структура предприятия - управление информацией в инновационной деятельности.

Одним из значительных показателей успешной инновационной деятельности является работа с информацией, оперативность, чистота прима-передачи и обработки. Любые преломления, проблемы восприятия, задержки или потери данных приводят к увеличению возможности возникновения рисковых ситуаций. Кроме того, немаловажным фактором является безопасности инновационной деятельности является и сохранность информации в рамках организации.

В связи с чем, наряду с организацией процессе управления инновациями в целом, необходимо разработать четкую информационную структуру компании на всех ее уровнях взаимодействия, которая включает в себя детальную проработку эффективности вертикального и горизонтального уровня информационных взаимодействий, оценку локализации и объемов информации, характеристику движения информационных потоков, благонадежность носителей информации и технологии минимизации и исключения воздействия информационных барьеров [4, 12].

3) Продукт - управление актуальностью

Один из основных рисков инновационной деятельности - неактуальность инновации для конечного потребителя, а также перенасыщение рынка аналогами.

На этапе планирования достаточно сложно предположить как одновременные открытия, так и изменения в потребительском поведении и ожиданиях.

В связи с чем, еще на стадии инициации инноваций необходимо формировать программу контроля актуальности продукта и рассматривать трансформационные возможности инновации.

Здесь важно отметить, что при разработке программ важно учитывать не только мнение экспертов или непосредственно разработчиков инновации, но и оценки конечного потребителя.

4) Технологии/ресурсы - управление возможностями

Дефицит ресурсов на любом этапе жизненного цикла инноваций - основная проблема ее эффективной реализации. 
В связи с чем, как при планировании инновационной деятельности, так и в процессе необходимо производить детальный анализ ресурсов по следующим критериям: наличие ресурсов инновационного проекта (производственных, материальных, технических, технологических, трудовых, интеллектуальных, финансовых, юридических и пр.), соответствие ресурсов уровню инновационной деятельности, а также их взаимозаменяемость и восполняемость.

Кроме того, важным моментов для успешной инновационной деятельности является возможность создания резервного фонда ресурсов.

5) Маркетинг/продвижение -управление спросом и предложением

Маркетинг определяется как общение, взаимодействие и формирование доверительных отношений с потребителями.

Если говорить, про маркетинг инновационной деятельности, то здесь, важным фактором выступает уникальность и неизвестность продукта для его потребителей. Соответственно, чаще всего, в маркетинге инноваций еще существует задача не только по продвижению инновации, но и по непосредственному формированию самого рынка создаваемого продукта и постоянной (на протяжении всего жизненного цикла инноваций) оценке его актуальности для потребителя.

В связи с этим компаниям-новаторам необходимо понимать стратегическое значение маркетинга для инновационной деятельности и разрабатывать концепцию анализа уже на этапе инициации инноваций.

6) Репутация - управление мнением

Репутация является одним из важнейших ресурсов компании, которая предоставляет возможность эффективного управления всеми опи- санными выше динамическими показателями.

При этом необходимо помнить, что репутация является также и одним из самых существенных рисков, так как ее потеря приносит компаниям глобальные убытки, а, возможно, и приводит к ее полной ликвидации.

Наиболее частой ошибкой организаций является перенос формирования репутации на более поздние периоды, на начальном этапе эта задача не считается первостепенной. В данном случае репутация и срабатывает впоследствии как риск, который либо невозможно исправить, либо это требует серьезных временных, эмоциональных и финансовых затрат.

Чтобы все-таки воспользоваться репутацией как основополагающим ресурсом, необходимо сразу, при планировании инновационной деятельности наряду с маркетинговыми мероприятиями компании-новатору разрабатывать репутационную карту организации и выстраивать четкие границы взаимодействий как внутри компании, так и за ее пределами [8].

В заключение хотелось бы отметить, что данные показатели определены как динамические ввиду их постоянных изменений на протяжении всего цикла инновационной деятельности. Соответственно, для успешной реализации инноваций, необходим постоянный контроль и оценка их эффективности, а также оперативное внесение изменений. Именно это позволит компании преодолеть (минимизировать последствия) в случае наступления непредвиденных и незапланированных ситуаций и, как результат, получить ожидаемый результат инновационной деятельности. Поэтому в своей работе мы сделали акцент именно на управлении всеми процессами, а не на их констатацию.

\section{Библиографический список}

1. Агарков С. А., Кузнецова Е. С., Грязнова М.О. Инновационный менеджмент и государственная инновационная политика. Изд: Академия Естествознания, 2011. Режим доступа https://www.monographies.ru/ru/book/ section?id=3768

2. Балабанов И. Т. Инновационный менеджмент. - СПб.: Питер, 2005. - 304 с

3. Нечаева Т.В. Стратегический подход к оценке рисков инновационных проектов // Микроэкономика. 2017. № 3. С. $18-23$.

4. Обеспечение экономической безопасности инновационной деятельности предприятия / Доронин С.Н., Васильев А. О., Буренкова Т. В. - Москва: МЦФЭР, 2006 (М.: Типография «Новости»). - 158 с.

5. Самолдин А. Н. Жизненный цикл инноваций // Вестник ГУУ. 2015. № 2. URL: https://cyberleninka.ru/article/n/ zhiznennyy-tsikl-innovatsiy (дата обращения: 05.12.2021).

6. Сергеева И.Г., Некрасова О.А. Классификация рисков инновационной деятельности / Успехи современной науки и образования. Том 3, № 11 (2016) 
7. Сураева М.О., КучерявенкоД. М. Тенденция развития корпоративного управления на предприятиях в условиях инновационной трансформации // Экономические исследования. 2020. Т. 6. № 4. C. 71-79. DOI: 10.18413/2409-1634-2020-6-4-0-8 [URL: http://rreconomic.ru/editorial-board/redactor/515/].

8. Сырова Т.Н. «Анализ рисков инновационной деятельности предприятия» / Актуальные аспекты развития современной науки: сборник научных статей Международной научной конференции, 19 дек. 2019 г. - Самара: Изд-во СГЭУ, 2019 г., с. 142-147

9. Сырова Т.Н. «Развитие инновационного потенциала персонала в целях правления рисками и инновационных проектов»/ Научный журнал «Известия Института систем управления СГЭУ» № 2 (18) 2018 (Самара) c. 36-38

10. Сырова Т.Н. «Прогнозируемые и непрогнозируемые риски в инновационной деятельности организаций» / Актуальные проблемы мирового научного пространства. Современный космос. Теория и практика: материалы международной научно-практической конференции (16 октября 2018 г.) Казань. Издательство ЦПМ «Академия бизнеса» (Саратов), 2018 - с. 121-124.

11. Трибушная B.X. Инновационная инфраструктура как необходимость поддержки наукоёмкого предпринимательства: технопарки и стратегическое управление: Монография. Ижевск, 2011. - 240 с.

12. Филиппов А.В. Принципы организации управления фирмой/ Пер. с англ. М.: АО АЭП, 1996-293 с. 